\title{
Ground as a source of heat for heat pumps
}

\section{Robert MATYSKO}

DOI: 10.30464/jmee.2018.2.2.131

Cite this article as:

Matysko R. Ground as a source of heat for heat pumps. Journal of Mechanical and Energy Engineering, Vol. 2(42), No. 2, 2018, pp. 131-138.

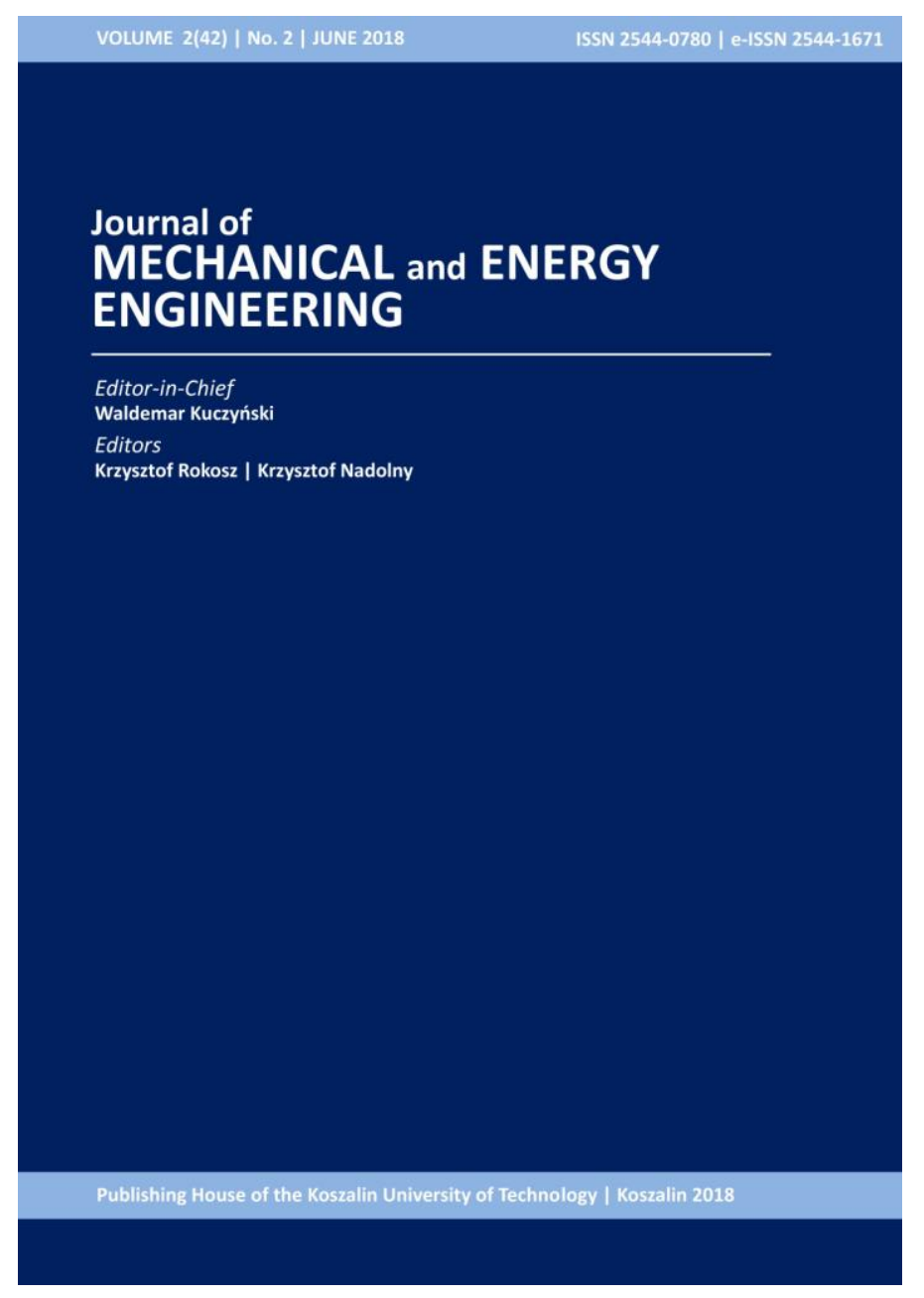

\section{Journal of Mechanical and Energy Engineering}

Website: jmee.tu.koszalin.pl

ISSN (Print): 2544-0780

ISSN (Online): 2544-1671

Volume: 2(42)

Number: 2

Year: 2018

Pages: 131-138

\section{Article Info:}

Received 6 March 2018

Accepted 18 April 2018

\section{Open Access}

This article is distributed under the terms of the Creative Commons Attribution 4.0 (CC BY 4.0) International License (http://creativecommons.org/licenses/by/4.0/), which permits unrestricted use, distribution, and reproduction in any medium, provided you give appropriate credit to the original author(s) and the source, provide a link to the Creative Commons license, and indicate if changes were made. 


\title{
GROUND AS A SOURCE OF HEAT FOR HEAT PUMPS
}

\author{
Robert MATYSKO ${ }^{1 *}$ \\ ${ }^{1 *}$ The Szewalski Institute of Fluid Flow Machinery, Polish Academy of Science, Turbine Department, Centre \\ of Heat and Power Engineering, matyskor@imp.gda.pl
}

(Received 6 March 2018, Accepted 18 April 2018)

\begin{abstract}
Heat pumps are an ideal solution for use in newly built passive and energy-plus buildings. One of the many problems present in such construction is the choice of the operational parameters of the lower heat source and the selection of a ground regeneration system which would enable effective regeneration in a short period of time and at a minimal cost. This article presents the heat analysis of the ground from which heat is obtained for heating purposes. The author also analyses ground heating, as the heat is delivered to it via regeneration systems. The presented in article results allow us to estimate the ground's thermal states based on lowered ambient temperature and the possible use of a lower heat pump source regeneration process. The original contribution in article is the calculation results of the ground behavior at the transient regeneration and heat consumption realized by the heat pump system.
\end{abstract}

Keywords: heat pump; ground heat exchanger, transient behaviour, ground regeneration

\section{INTRODUCTION}

Heat pumps are an ideal solution for use in newly built passive and energy-plus buildings. The paper [1] presents an Organic Rankine Cycle (ORC)-assisted with ground source heat pump for the utilization of low-grade energy and shallow geothermal energy in cold regions. During the heating season, the combined system is realized space heating process, and during the non-heating season, the ORC unit is connected to ground heat exchangers for seasonal storage. The paper [2] analyzes a new type of underground water source heat pump system, making the groundwater source heat pump system more efficient and energy saving. The application and performance of ground source heat pump (GSHP) systems in Jiangsu, China are reported in [3], and the experimental and theoretical methodologies are selected to investigate the operating performance of a ground heat exchanger made of polyethylene material which can face acid environment in [4]. The [5] paper shows the results of an invertible ground source heat pump (GSHP) with borehole heat exchangers. A minitype ground source heat pump (GSHP) system was presented in [6]. The ground heat exchanger consists of 9 vertical boreholes. Paper [6] reported that in winter conditions, the ground-coupled exchanger of the lower heat pump source has a tendency toward long-term ground freezing, especially if the heat exchange surface is not correctly selected. Paper [7] explains why the steady periodic temperature profile should be used for sizing ground heat exchanger for efficient operation of ground source heat pumps for longer periods of time. The work [8] has the objective of analyzing the potential of use of a municipal solid waste landfill for space heating through a heat pump with horizontal pipes. A dynamic model has been created in [8] for a real case study of a municipal solid waste landfill located in the north-east of Italy. The year-round performance of a ground source heat pump (GSHP) with multiple energy piles (EPs) is investigated in the [9] study based on a 3D transient heat transfer model. Subsurface shallow depth soil layer (SSDSL) is characterized by dynamic temperature changes, which may be eligible to constitute as a heat source for ground heat pumps. The [10] paper present the regime of heat flow in SSDSL and its climatic conditions in central Europe, taking into consideration the agriculture periphery characteristics of Wroclaw (Poland). The work [11] evaluates the thermal behavior of ground source heat pumps in cold climates, where the thermal load profile of buildings is not balanced between heating and cooling, especially 
in residential sector characterized by low internal loads. A hybrid ground source heat pump system to extract heat from ground and the appropriate simulation model was developed considering the dynamic performance of heat pump and the heat transfer of heat pipes and surrounded soil is proposed in the work [12]. The large imbalances between cooling and heating loads cause a rise or decline in ground temperature because of thermal interference between multiple ground heat exchangers (GHEs). The annual changes caused by the thermal interference in ground was presented in the paper [13]. The [14] paper focuses on combining a ground source heat pump system with a solar thermal array, for eliminating the effect of ground thermal imbalance. The heat compensation unit with thermosyphon has been described in [15] to eliminate the annual soil thermal imbalance of ground-coupled heat pump in heating-dominant buildings. The objective of the [16] study is to investigate the influence of the cooling performance for a water-to-water ground source heat pump (GSHP) by using the counter flow and parallel flow methods. A novel heating and power cogeneration system coupling biomass partial gasification and ground source heat pump is proposed and analyzed in the [17] study. The proposed in [17] system consists of four subsystems: biomass partial gasification subsystem; gas turbine power generation subsystem; steam turbine power generation subsystems; and ground source heat pump subsystem. The exergetic and exergoeconomic performance analysis of proposed system are investigated in [18]. The paper [19] presents an experimental investigation and control optimization of a ground source heat pump (GSHP) system. The work [20] presents long-term operation of a ground-source heat pump (GSHP) under a load imbalance condition with can lead to thermal buildup or depletion. One of the many problems present in such constructions of the ground heat exchangers is the choice of the operational parameters of the lower heat source and the selection of a ground regeneration systems which would enable effective regeneration in a short period of time and at a minimal cost. Regeneration process can reduce of the imbalance and the ground thermal depletion. The next chapter presents a theoretical model and calculations for the exploitational conditions for the ground with horizontally heat exchangers.

\section{ASSUMPTIONS FOR THE THERMAL GROUND ANALYSIS AND THE MATHEMATICAL MODEL}

For the calculations it was assumed that the heat energy is obtained through the horizontal collector of a ground-coupled heat exchanger with ethyl alcohol or propylene glycol as the operating medium, in a closed circuit. This variant also included the phenomenon of the gradual depreciation of the gradient of the ground temperature, which causes a permanent decrease in the ground's energy efficiency. To minimize the effect of the gradual cooling of the ground, it is necessary to properly balance the energy model. For this purpose, one must take into account the ground's regeneration time to protect its energy resources. We assume that the regeneration of the lower source takes place in the summer period through direct heating with solar energy and ground water flowing directly in the vicinity of the horizontal heat exchanger. Possible variants of lower source regeneration systems include solar systems, waste heat from AC systems and other high-energy sources.

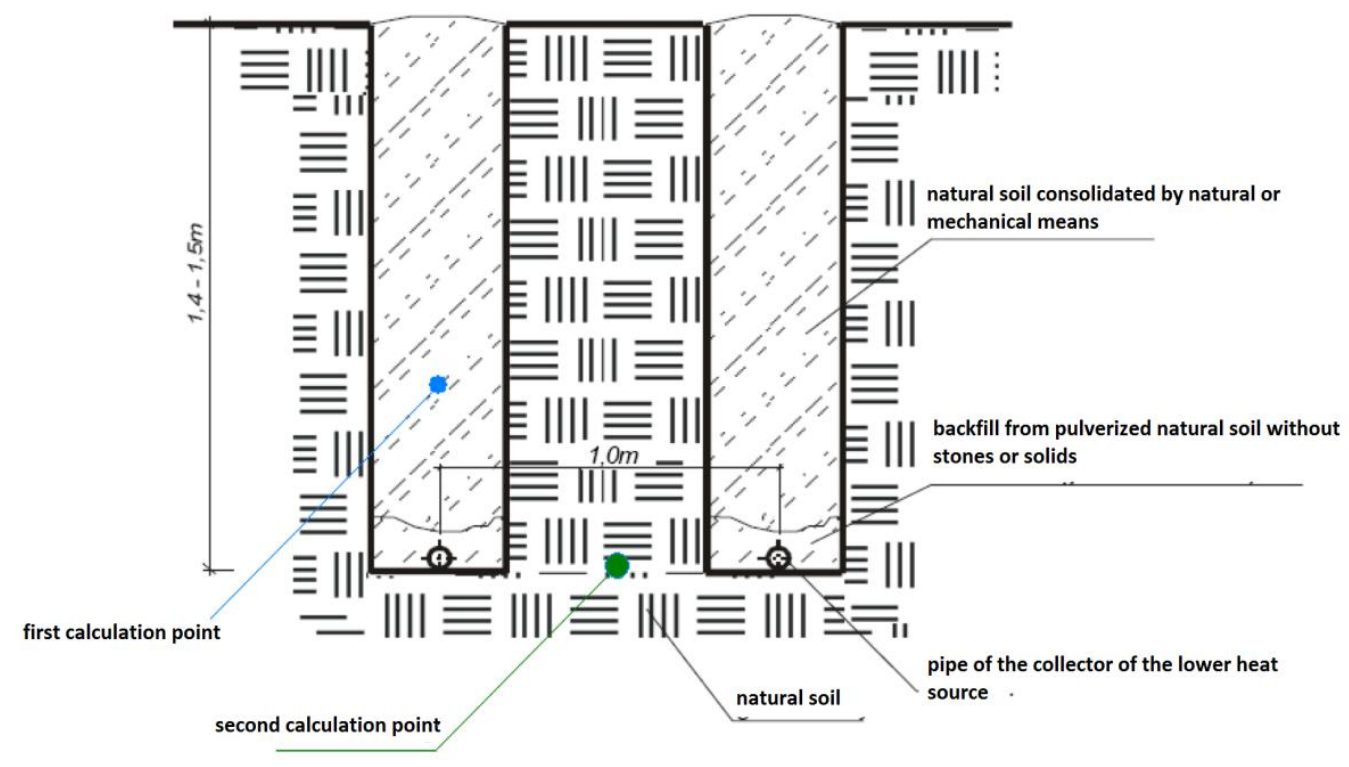

Fig. 1. Geometric layout of the ground-coupled exchanger and the calculation points for the ground's heat dynamics 
The input data for the ground analysis:

- geometric layout of pipes in the ground-coupled exchanger is shown on Fig. 1,

- submersion of horizontal lower heat source pipelines 1.2-1.4 m,

- design external temperature in winter $T_{\text {winter }}=-251.15 \mathrm{~K}$,

- scope of operating temperatures of the lower heat source $T=278.15-288.15 \mathrm{~K}$,

- fine-grained sands are present at the depth of 0-5 m,

- pipe diameter $\phi=0.04 \mathrm{~m}$,

- the calculations were performed for a medium medium-moist sand $\lambda=0.4 \mathrm{~W} / \mathrm{m} / \mathrm{K}$ (PN-EN ISO 6946).

Table 1 shows the heat properties of the ground used in the calculations.

Tab. 1. Ground heat properties used in the calculations

\begin{tabular}{|c|c|c|}
\hline Parameter name & Quantity & Unit \\
\hline $\begin{array}{l}\text { specific heat of the ground } \\
\text { (sand) }\end{array}$ & 840 & $\mathrm{~J} / \mathrm{kg} / \mathrm{K}$ \\
\hline density of the ground (sand) & 1600 & $\mathrm{~kg} / \mathrm{m}^{3}$ \\
\hline $\begin{array}{l}\text { heat capacity of the ground } \\
\text { (sand) }\end{array}$ & 1.34 & $\mathrm{MJ} / \mathrm{m}^{3} / \mathrm{K}$ \\
\hline specific heat of the water & 190 & $\mathrm{~J} / \mathrm{kg} / \mathrm{K}$ \\
\hline water density & 1000 & $\mathrm{~kg} / \mathrm{m}^{3}$ \\
\hline heat capacity of water & 4.19 & $\mathrm{MJ} / \mathrm{m}^{3} / \mathrm{K}$ \\
\hline $\begin{array}{l}\text { heat capacity of wet ground } \\
(1 / 3 \text { water }+2 / 3 \text { sand })\end{array}$ & 2.29 & $\mathrm{MJ} / \mathrm{m}^{3} / \mathrm{K}$ \\
\hline
\end{tabular}

The following basic thermal conduction dynamics equation was used for the calculation of the change in ground temperature:

$$
\rho C_{p} \frac{\partial T}{\partial t}=\nabla \cdot(k \nabla T)
$$

where:

$\rho$ - density $\left[\mathrm{kg} / \mathrm{m}^{3}\right]$,

$C_{p}$ - specific heat $[\mathrm{J} / \mathrm{kg} / \mathrm{K}]$,

$T$ - ground temperature $[\mathrm{K}]$,

$k$ - heat transfer coefficient $\left[\mathrm{W} / \mathrm{m}^{2} / \mathrm{K}\right]$,

$t$ - time [s].

The boundary condition for the lower heat source was defined by the equation:

$$
-\mathbf{n} \cdot\left(-k \nabla T_{b}\right)=h \cdot\left(T_{e x t}-T_{b}\right),
$$

where:

$h$ - heat transfer coefficient of the external fluid film $[\mathrm{W} / \mathrm{m} / \mathrm{K}]$,

$k$ - heat transfer coefficient $\left[\mathrm{W} / \mathrm{m}^{2} / \mathrm{K}\right]$,

$T_{b}$ - boundary temperature [K],

$T_{\text {ext }}$ - temperature of the external fluid [K], n - normal vector to the heat transfer surface.

This equation assumes the open boundary conditions for the ground.

Two characteristic points were used to verify the calculations:

- first point at the depth of $1 \mathrm{~m}$, located centrally over the pipe,

- second point at the depth of $1.5 \mathrm{~m}$, located between two pipes of the ground-coupled heat exchanger.

\section{RESULTS OF THE HORIZONTAL GROUND-COUPLED HEAT EXCHANGER CALCULATIONS.}

This chapter presents the results of the lower heat source calculations related to the cooling and regeneration of ground. The initial calculation values are presented in Table 2 .

Tab. 2. Initial values for the heat calculations regarding ground cooling and regeneration

\begin{tabular}{lc}
\hline \multicolumn{2}{c}{ Ground cooling } \\
\hline Initial temperature & $T_{\text {start }}=288.15 \mathrm{~K}$ \\
\hline Ambient temperature & $T_{o t}=251.15 \mathrm{~K}$ \\
\hline $\begin{array}{l}\text { Temperature of the ground- } \\
\text { coupled heat exchanger }\end{array}$ & $T_{g r}=278.15 \mathrm{~K}$ \\
\hline \multicolumn{1}{c}{ Ground regeneration } \\
\hline Initial temperature & $T_{\text {start }}=265.15 \mathrm{~K}$ \\
\hline Ambient temperature & $T_{o l}=298.15 \mathrm{~K}$ \\
\hline $\begin{array}{l}\text { Temperature of the ground- } \\
\text { coupled heat exchanger }\end{array}$ & $T_{g r}=300.15 \mathrm{~K}$ \\
\hline
\end{tabular}

Figure 2 shows the calculations of the dynamic temperature change for the two characteristic points located at different depths. Fig. 2a shows the process of ground cooling based on the assumption that the lower heat source operates continuously. Fig. 2b shows the process of ground heating based on the assumption that the upper heat source operates continuously. Fig. 3 shows the distribution of the temperature contours for the time $t=1 \mathrm{e} 5 \mathrm{~s}$ and $t=1 \mathrm{e} 7 \mathrm{~s}$ during ground cooling. Figure 4 shows the distribution of the temperature contours for the time $t=1 \mathrm{e} 5 \mathrm{~s}$ and $t=1 \mathrm{e} 7 \mathrm{~s}$ during ground regeneration.

The distribution visible on fig. 3 and 4 clearly shows how the temperature front moves in the ground due to the operation of the ground-coupled exchanger during ground cooling and heating.

Ground temperature $273,15 \mathrm{~K}$ at the depth of 1 metre will be reached after $1.75 \mathrm{e} 6$ (20 days) in the case of the continuous operation of the lower heat source ( $24 \mathrm{~h} /$ day) with an ambient temperature of 251 $\mathrm{K}$ and the lower heat source temperature at the level of 278,15 K (Table 1). 
a)

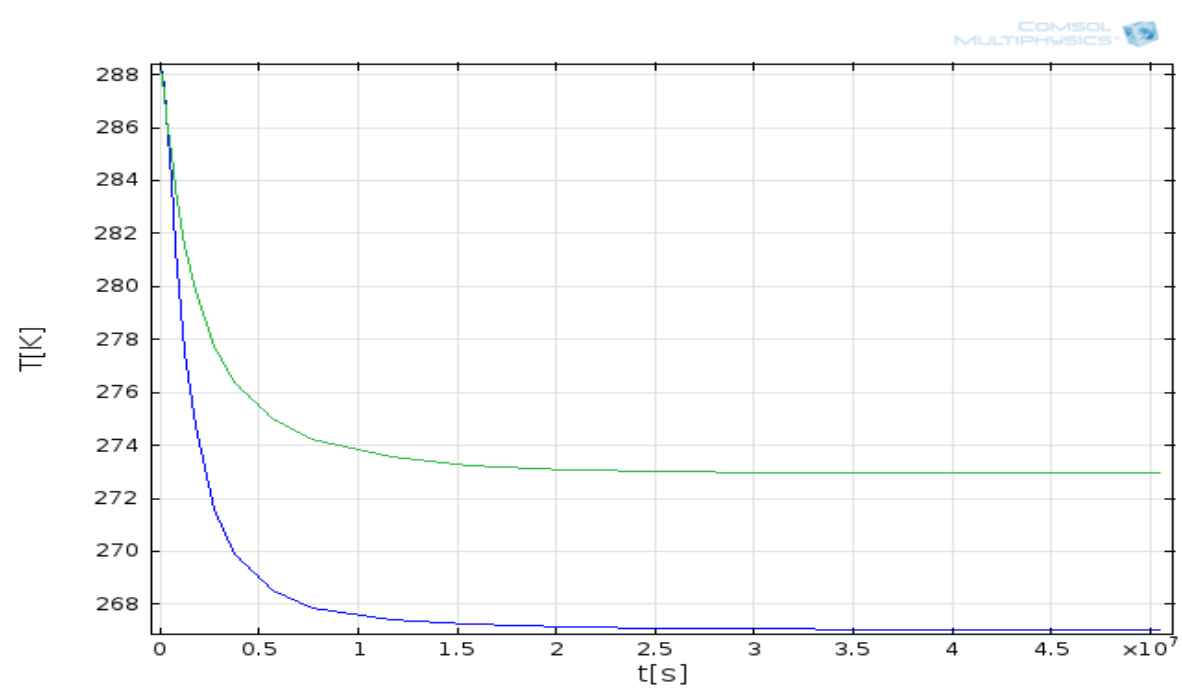

b)

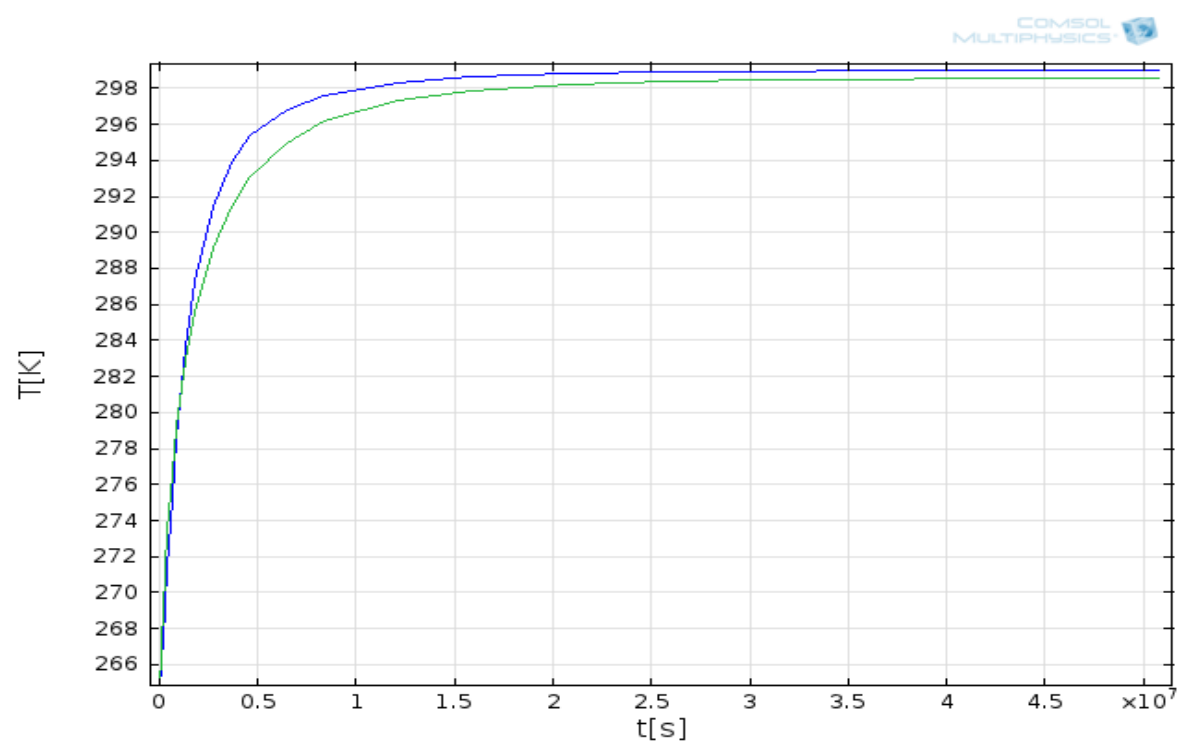

Fig. 2. Temperature changes in time for the depth $1 \mathrm{~m}$ (blue) and $1.5 \mathrm{~m}$ (green) during ground cooling (a) and regeneration (b)

At the depth of $1.5 \mathrm{~m}$, the freezing point $273,15 \mathrm{~K}$ is reached after 2.05e7 (237 days) of constant operation. In the case of the use of a regeneration system, in summer the operational parameters of the ground should be restored to $283 \mathrm{~K}$ after approx. 15 days of the system's constant operation.

\section{CONCLUSIONS}

The presented calculation results allow us to estimate the ground's thermal states based on lowered ambient temperature and the possible use of a lower heat pump source regeneration process.
The model does not include the influence of watercourses in the ground (unfavorable variant) on the heat conduction processes. It was assumed that there are no watercourses in the ground and no phase transition water crystallization process takes place. As a result, in the ground cooling process below $273,15 \mathrm{~K}$ temperature can be reached in a longer time due to moisture diffusion in the ground as well as the change of water from the liquid phase to the crystalline phase, which is related to the heat of the freezing phase transition and the time of this transition, which is dependent on the moisture content of the ground. 
a)

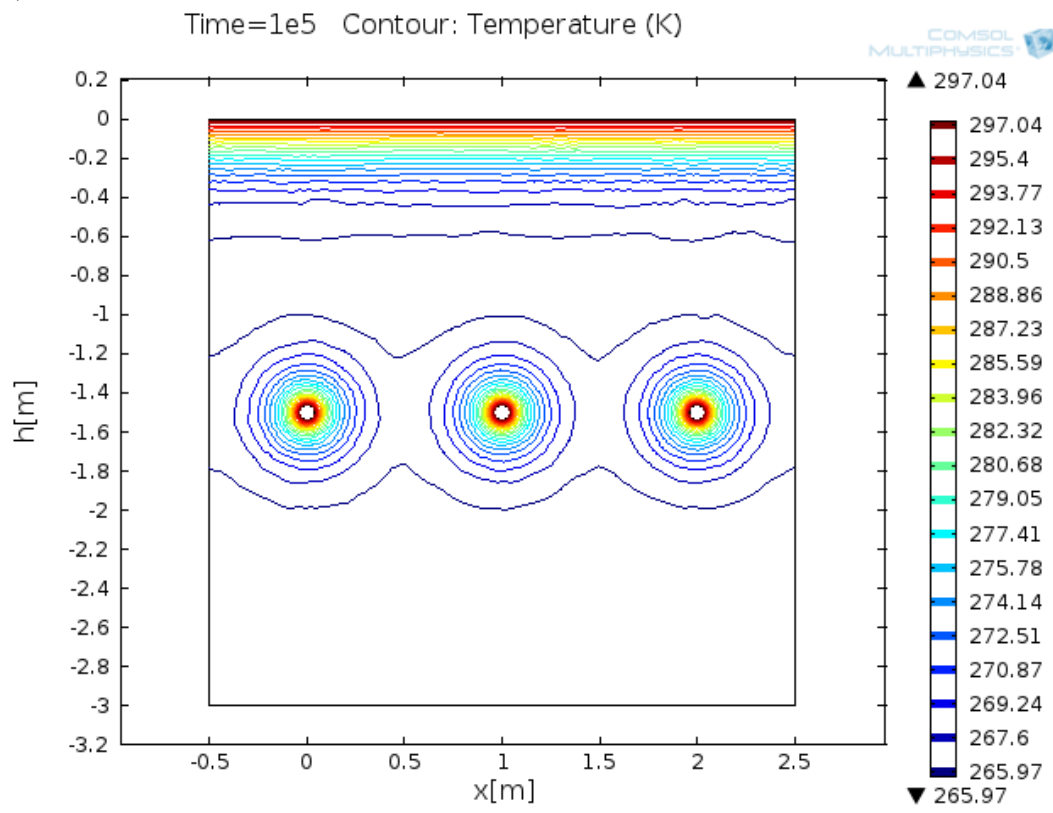

b)

Time=1e7 Contour: Temperature (K)

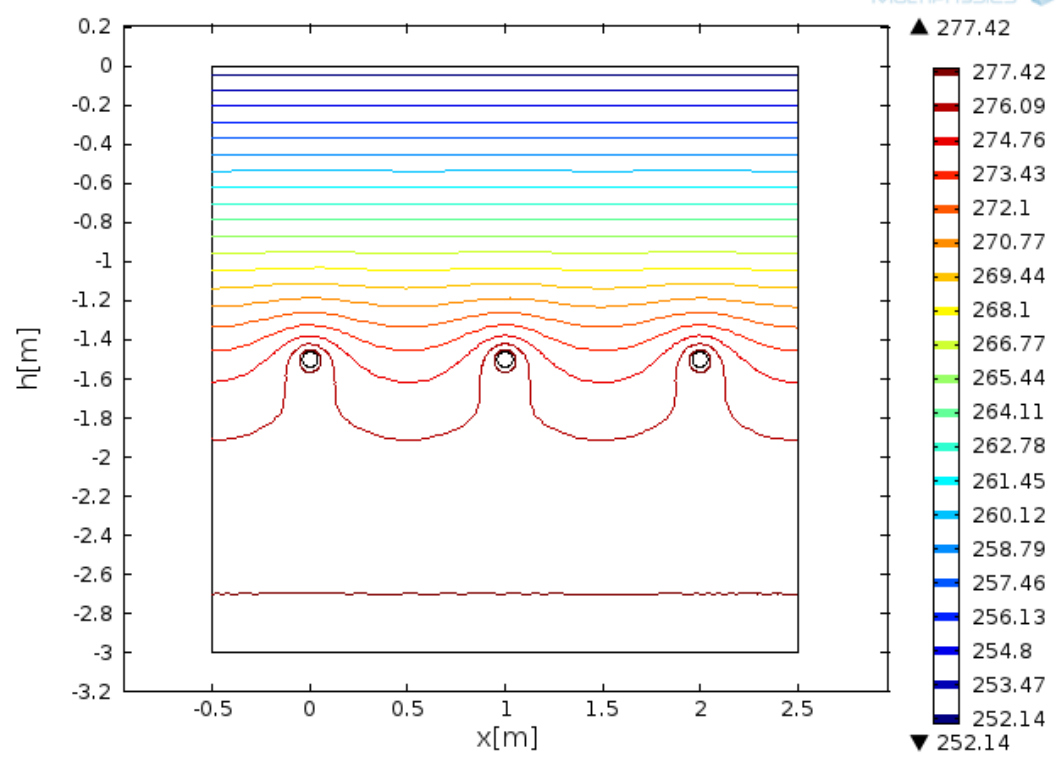

Fig. 3. Temperature distribution for ground cooling for the time: a) $t=1 \mathrm{e} 5 \mathrm{~s}$; b) $t=1 \mathrm{e} 7 \mathrm{~s}$

However, assuming the predicted operation period of 40-50 years, in the case of extremely low ambient temperatures in winter and excessive moisture penetration, the ground-coupled heat exchanger may experience local freezing with the formation of ice wreaths which with time can form a type of ice "plate" within the ground structure. At the depth of $1.5 \mathrm{~m}$, the freezing point $273,15 \mathrm{~K}$ is reached after 237 days of constant operation. For horizontal ground-coupled exchangers this is a negative phenomenon, which is why one of the recommended solutions in such cases is the use of regeneration systems. In the case of the use of a regeneration system, in summer the operational parameters of the ground should be restored to $283,15 \mathrm{~K}$ after approx. 15 days.

Fig. 4. Nomenclature

$$
\begin{array}{ll}
C_{p} & \text { - specific heat } \\
h & \text { - heat transfer coefficient } \\
k & \text { - thermal conductivity } \\
T & \text { - temperature } \\
t & \text { - time } \\
\rho & \text { - density }
\end{array}
$$


a)

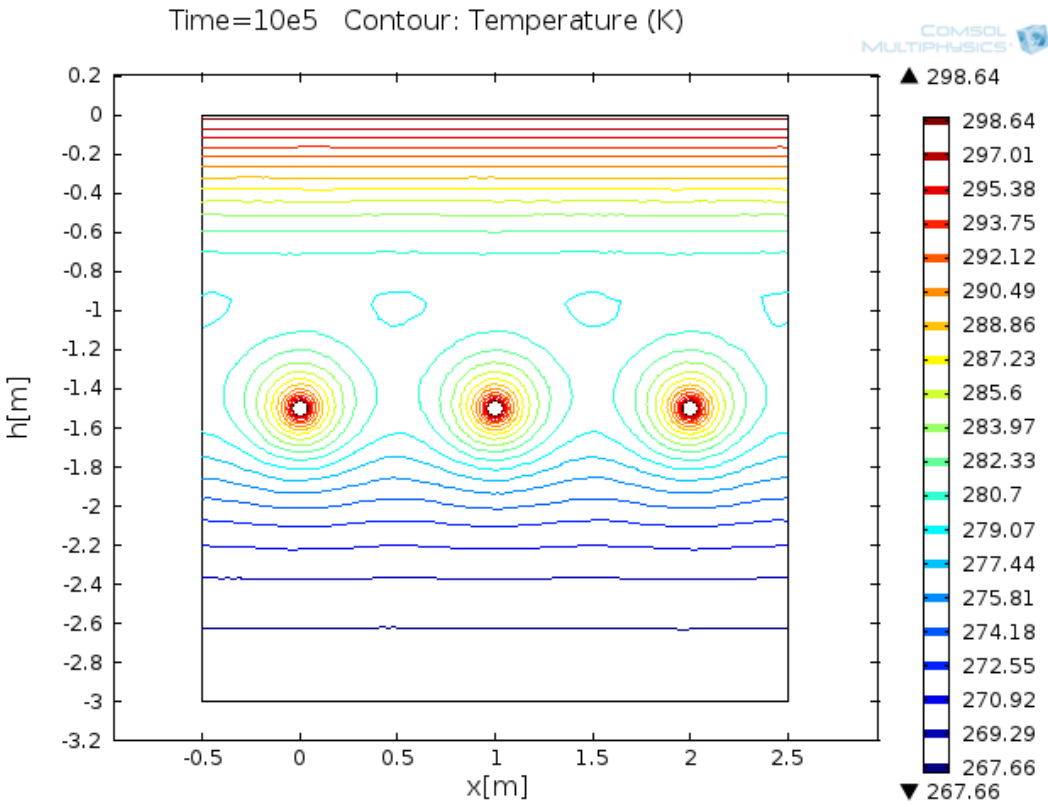

b)

Time $=1$ e 7 Contour: Temperature (K)

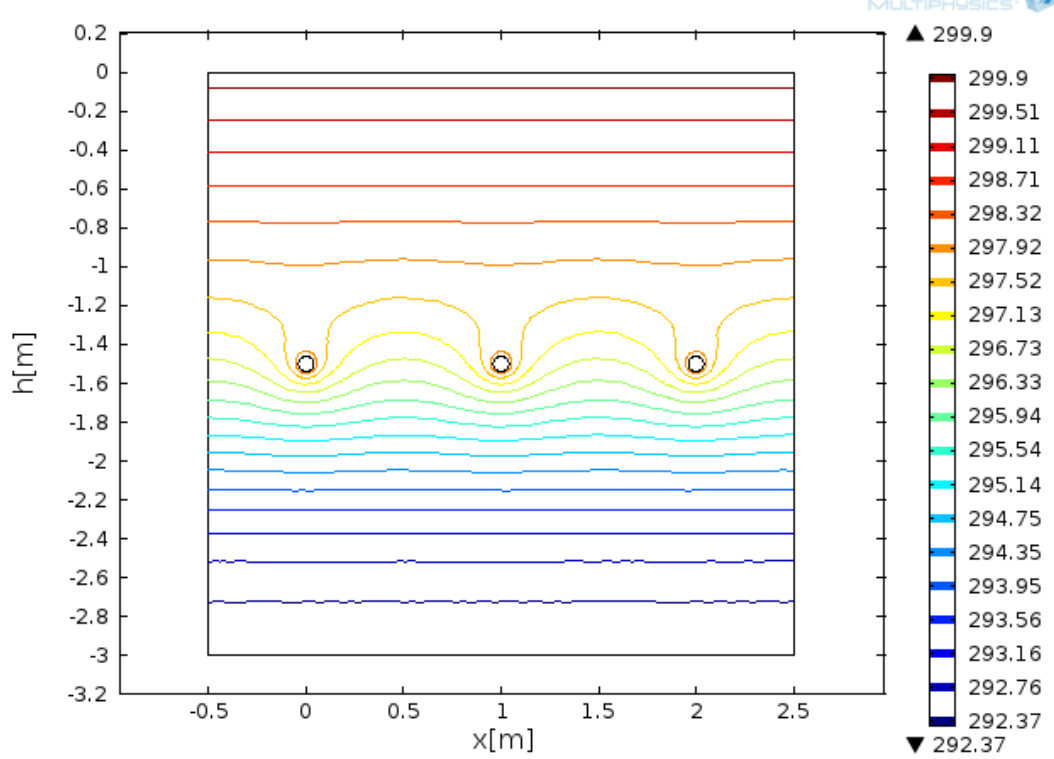

Fig. 5. Temperature distribution for ground regeneration for the time $t=10 \mathrm{e} 5 \mathrm{~s} \mathrm{(a)}$ and $t=1 \mathrm{e} 7 \mathrm{~s} \mathrm{(b)}$

\section{References}

1. Weiyi Li, Xinxing Lin, Chunhui Cao, Zhida Gong, Yan Gao, Organic Rankine Cycle-assisted ground source heat pump combisystem for space heating in cold regions, Energy Conversion and Management, 165, (2018), 195205

2. Zhiqiang Kang, Xiaoxi Zhou, Yiyang Zhao, Ruiting Wang, Xiaoyue Wang, Study on Optimization of Underground Water Source Heat Pump, Procedia Engineering, 205, (2017), 1691-1697

3. Shuyang Zhang, Lun Zhang, Xiaosong Zhang, Performance evaluation of existed ground source heat pump systemsin buildings using auxiliary energy efficiency index: Cases study in Jiangsu, China Energy and Buildings, 147, (2017), 90-100

4. Bo Cai, Hongqiang Li, Yan Hu, Lifang Liu, Jie Huang, Andrea Lazzaretto, Guoqiang Zhang, Theoretical and experimental study of combined heat and power (CHP) system integrated with ground source heat pump (GSHP), Applied Thermal Engineering, 127, (2017), 16-27

5. Luigi Schibuola, Massimiliano Scarpa, Ground source heat pumps in high humidity soils: An experimental analysis, Applied Thermal Engineering, 99, (2016), 80-91 
6. X.Q. Zhai, X.W. Cheng, R.Z. Wang .Heating and cooling performance of a minitype ground source heat pump system, Applied Thermal Engineering, 111, (2017), 1366-1370

7. Nurullah Kayaci, Hakan Demir, Numerical modelling of transient soil temperature distribution for horizontal ground heat exchanger of ground source heat pump, Geothermics, 73, (2018), 33-47

8. Giuseppe Emmi, Angelo Zarrella, Anna Zuanetti, Michele De Carli, Use of municipal solid waste landfill as heat source of heat pump, Energy Procedia, 101, (2016), $352-359$

9. Yuanlong Cui, Jie Zhu, Year-round performance assessment of a ground source heat pump with multiple energy piles, Energy and Buildings, 158, (2018), 509524

10. Krystyna Bryś , Tadeusz Bryś , MarderosAra Sayegh, Hanna Ojrzyńska Subsurface shallow depth soil layers thermal potential for ground heat pumps in Poland Energy \& Buildings 165 (2018) 64-75

11. Giuseppe Emmi, Angelo Zarrella, Michele De Carli, Antonio Galgaro, Solar Assisted Ground Source Heat Pump in Cold Climates, Energy Procedia, 82, (2015), $623-629$

12. Xiaoyuan Wang, Yinfeng Wang, Zhi Wang, Yuxuan Liu, Yuezhao Zhu, Haijun Chen, Simulation-based analysis ofaground source heatpump systemusing superlong flexible heat pipes coupled borehole heat exchanger during heating season, Energy Conversion and Management, 164, (2018), 132-143

13. Sayaka Kindaichi, Daisaku Nishina, Simple index for onsite operation management of ground source heat pump systems in cooling-dominant regions, Renewable Energy, 127, (2018), 182-194

14. Jamie P. Fine, Hiep V. Nguyen, Jacob Friedman, Wey H. Leong, Seth B. Dworkin, A simplified ground thermal response model for analyzing solar-assisted ground source heat pump systems, Energy Conversion and Management, 165, (2018), 276-290

15. Tian You, Xianting Li, Wei Wu, Wenxing Shi, Baolong Wang, Kenichi Soga Coupled heating of ground-coupled heat pump system with heat compensation unit: Performance improvement and borehole reduction Energy Conversion and Management 148 (2017) 57-67

16. Ohkyung Kwon, KyungJin Bae

17. , Chasik Park Cooling characteristics of ground source heat pump with heat exchange methods Renewable Energy 71 (2014) 651-657

18. Hongqiang Li, Xiaofeng Zhang, Lifang Liu, Shuang Wang, Guoqiang Zhang Proposal and research on a combined heating and power system integrating biomass partial gasification with ground source heat pump Energy Conversion and Management 145 (2017) $158-168$

19. Xiaofeng Zhang, Hongqiang Li, Lifang Liu, Chengying Bai, Shuang Wang, Quanbin Song, Jing Zenga, Xiaobo Liua, Guoqiang Zhang Exergetic and exergoeconomic assessment of a novel CHP system integrating biomass partial gasification with ground source heat pump Energy Conversion and Management 156 (2018) 666-679

20. Lei Xia, Zhenjun Ma, Craig McLauchlan, Shugang Wang, Experimental investigation and control optimization of a ground source heat pump system, Applied Thermal Engineering 127 (2017) 70-80

21. Wonjun Choi, Ryozo Ooka, Yujin Nam, Impact of longterm operation of ground-source heat pump on subsurface thermal state in urban areas Sustainable Cities and Society 38 (2018) 429-439

\section{Biographical note}

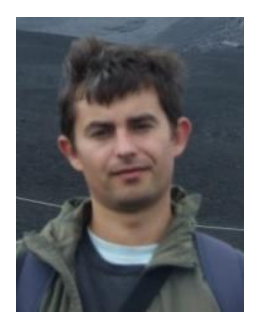

Robert Matysko is a graduate of the $\mathrm{PhD}$ study at the Faculty of Mechanical Engineering at the Koszalin University of Technology. He obtained the doctoral title in the field of Construction and Exploitation of Machines at the Koszalin University of Technology and then took a job at the Institute of Fluid-Flow Machinery of the Polish Academy of Sciences in Gdańsk. At the Institute of Fluid-Flow Machinery he obtained the title of the $\mathrm{dr}$ hab. Eng. in the field of Construction and Exploitation of Machines. He was the coordinator in the investment of the Research Center of the Polish Academy of Sciences in Jabłonna. He also managed the Department of Thermodynamics at IFFM-PAS. Scientific interests are related to the control and modeling of thermodynamic processes. Currently, he develops algorithms for controlling various autonomous systems. 
